\title{
Two Benchmarks for Qualification of Pressure Vessel Fluence Calculational Methodology
}

\section{Remec}

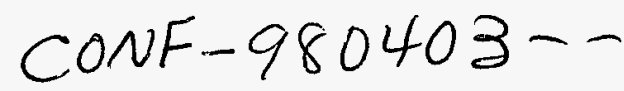

\begin{abstract}
Two benchmarks for the qualification of the pressure vessel fluence calculational methodology were formulated and are briefly described. The Pool Critical Assembly (PCA) benchmark is based on the experiments performed at the PCA in Oak Ridge. The measured quantities to be compared against the calculated values are the equivalent fission fluxes at several locations in front, behind, and inside the pressure-vessel wall simulator. This benchmark is particularly suitable to test the capabilities of the calculational methodology and cross-section libraries to predict in-vessel gradients because only a few approximations are necessary in the analysis.

The HBR-2 benchmark is based on the data for the H. B. Robinson-2 plant, which is a $2300 \mathrm{MW}$ (thermal) pressurized light-water reactor. The benchmark provides the reactor geometry, the material compositions, the core power distributions, and the power history data. The quantities to be calculated are the specific activities of the radiometric monitors that were irradiated in the surveillance capsule and in the cavity location during one fuel cycle. The HBR-2 benchmark requires modelling approximations, power-to-neutron source conversion, and treatment of time dependant variations. It can therefore be used to test the overall performance and adequacy of the calculational methodology for power-reactor pressure-vessel flux calculations.

Both benchmarks were analyzed with the DORT code and the BUGLE-96 cross-section library that is based on ENDF/B-VI evaluations. The calculations agreed with the measurements within $\sim 10 \%$, and the calculations underpredicted the measurements in all the cases. This indicates that the ENDF/B-VI cross sections resolve most of the discrepancies between the measurements and calculations. The decrease of the $\mathrm{C} / \mathrm{M}$ ratios with increased thickness of iron, which was typical for pre-ENDF/B-VI libraries, is almost completely removed.
\end{abstract}

\section{INTRODUCTION}

The calculational methods for determining fluence at the nuclear reactor pressure vessels and surveillance capsules are complex, the input data have considerable uncertainties, and approximations in modeling are usually needed. Yet accurate fluence values are necessary to assess and predict vessel material embrittlement and assure safe operation of the plants. For these reasons the U. S. Nuclear Regulatory Commission Draft Regulatory Guide DG-1053 entitled "Calculational and Dosimetry Methods for Determining Pressure Vessel Neutron Fluence" requires qualification of the calculational methodology.

One step of the qualification is the analysis of benchmarks. To provide input, which may be used to fulfill part of this step, two benchmarks were prepared. The formulation of the PCA and HBR-2 benchmarks is given in NUREG reports ${ }^{1.2}$. These reports provide condensed, yet self-sufficient and complete data necessary for the benchmark analysis. The reports include the dimensions, material compositions, and neutron source, as well as the measured quantities to be compared with the calculated values and an example of the benchmark analysis. In the following some characteristics of the benchmarks will be described and results of the analysis will be presented.

\section{DESCRIPTION OF THE BENCHMARKS}

\subsection{PCA BENCHMARK}

The PCA benchmark is based on the experiments performed during 1978-1981 at the Pool Critical Assembly (PCA) in Oak Ridge ${ }^{3}$. A horizontal cross section of the PCA pressure vessel wall benchmark facility is shown in Fig. 1. The facility consisted of the PCA reactor core and the components that mocked up the core-to-cavity region in light water reactors. These components were a thermal shield, a pressure vessel simulator, and a void box which simulated the reactor cavity. The thicknesses of the water gaps between the aluminum window and thermal shield, and between the thermal shield and pressure vessel, are approximately $12 \mathrm{~cm}$ and $13 \mathrm{~cm}$, respectively. For this reason the configuration used for the benchmark was labeled a 12/13 configuration. Stainless steel was used for the thermal shield, and carbon

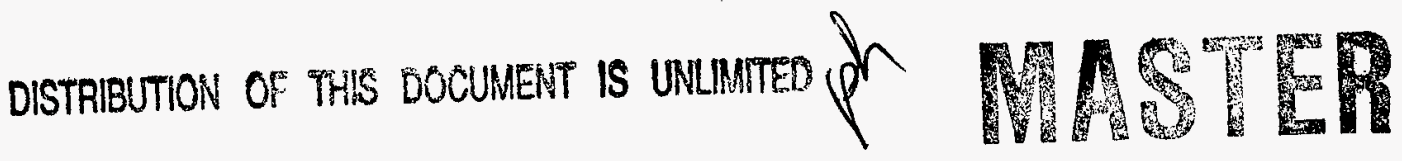




\section{DISCLAIMER}

This report was prepared as an account of work sponsored by an agency of the United States Government. Neither the United States Government nor any agency thereof, nor any of their employees, makes any warranty, express or implied, or assumes any legal liability or responsibility for the accuracy, completeness, or usefulness of any information, apparatus, product, or process disclosed, or represents that its use would not infringe privately owned rights. Reference herein to any specific commercial product, process, or service by trade name, trademark, manufacturer, or otherwise does not necessarily constitute or imply its endorsement, recommendation, or favoring by the United States Government or any agency thereof. The views and opinions of authors expressed herein do not necessarily state or reflect those of the United States Government or any agency thereof. 
steel for the pressure vessel. The facility was located in a large pool of water, which serves as reactor core coolant and moderator and provides shielding. The water temperature was approximately $38^{\circ} \mathrm{C}$.

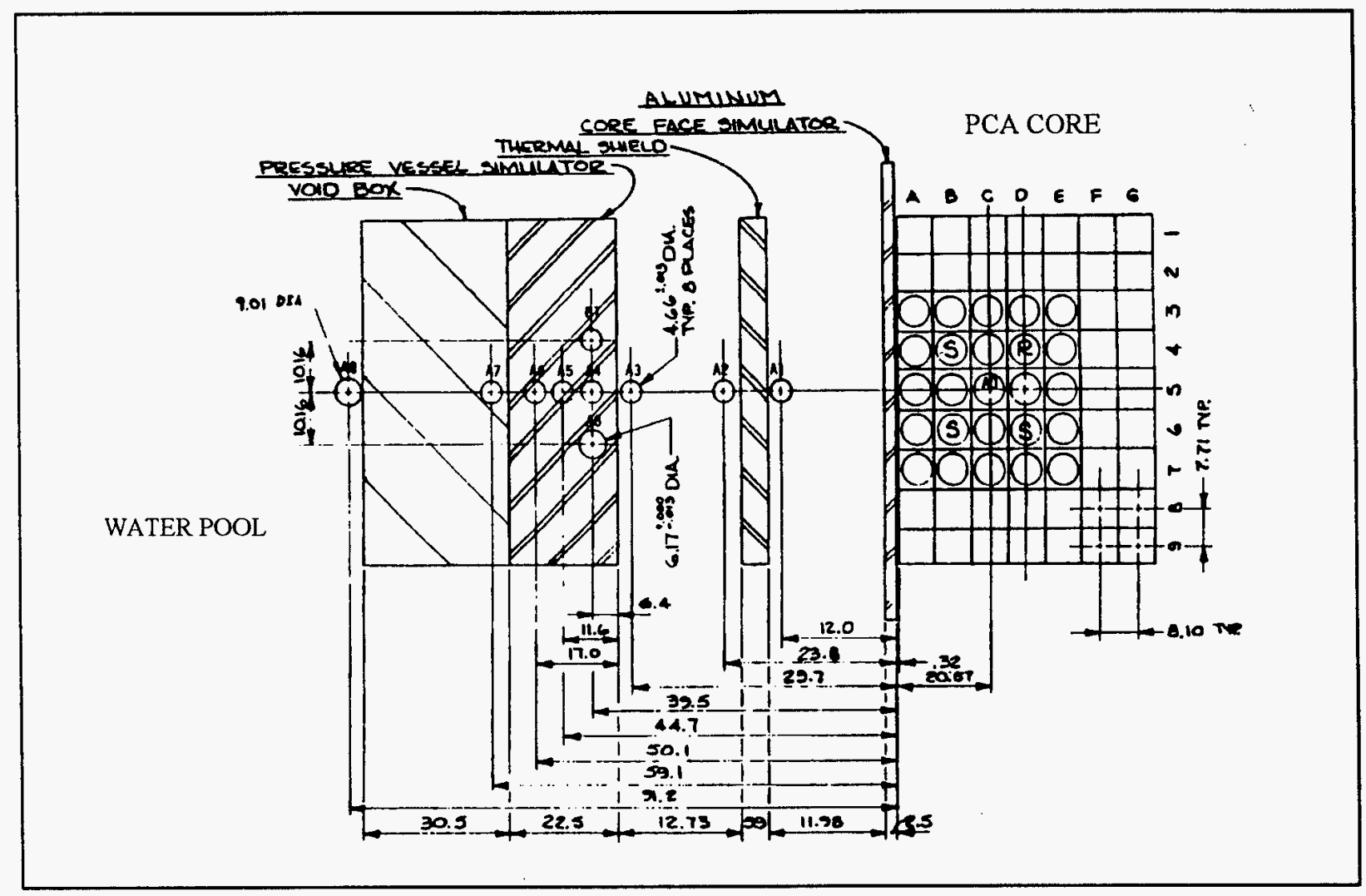

Fig. 1 Horizontal cross section of the PCA pressure vessel benchmark facility. (Dimensions are in $\mathrm{cm}$.)

The PCA core consisted of 25 materials-testing-reactor plate-type fuel elements with highly enriched (93\%) ${ }^{235} \mathrm{U}$ fuel. Fresh fuel was used with essentially no fission products present. On the first row facing the experiment, only the fuel elements of the same type and containing equal masses of ${ }^{235} \mathrm{U}$ were loaded, and quarter-core symmetry was maintained. The core power distribution was carefully characterized using a combination of fission chamber measurements and core calculations. In the benchmark the power distribution is specified as a product of cosine-shaped distribution in the vertical direction and a distribution in the horizontal plane, which is given with an array of relative power densities $(3 \times 3$ values per fuel element) and relative fuel element powers.

Measurements were performed at the core midplane at several locations, labeled in Fig. 1 as Al to A7. Reaction rates for the ${ }^{103} \mathrm{Rh}\left(n, n^{7}\right)^{103 \mathrm{~m}} \mathrm{Rh},{ }^{115} \mathrm{In}(n, n)^{115 \mathrm{~m}} \mathrm{In},{ }^{58} \mathrm{Ni}(n, p)^{58} \mathrm{Co}$, and ${ }^{27} \mathrm{Al}(n, \alpha)^{24} \mathrm{Na}$ reactions were measured with radiometric monitors, while fission chambers were used for the ${ }^{237} \mathrm{~Np}(n, f)$ and ${ }^{238} \mathrm{U}(n, f)$ reactions. The neptunium and uranium fission rates were corrected for the photofission. Measured reaction rates were reported in terms of equivalent ${ }^{235} \mathrm{U}$ fission fluxes which are listed in Table 1. The tabulated values and uncertainties are in most cases based on several measurements by different experimenter teams. Table 1 also gives the reaction cross sections averaged over a ${ }^{235} U$ fission spectrum. The cross sections were used to convert the reaction rates into equivalent fission fluxes.

The experimental access tubes in which the measurements were done were filled with appropriate material (steel in the pressure vessel locations and Plexiglas in the in-water locations) in order to minimize the perturbations of the neutron field. For the purpose of the benchmark analysis the measurements can therefore be considered as having been done in the unperturbed medium. 
Table 1. Equivalent fission fluxes ${ }^{l}$ (per 1 PCA core fission neutron per second $\left(\mathrm{cm}^{-2}\right)$ )

\begin{tabular}{|c|c|c|c|c|c|c|c|}
\hline Location & $\begin{array}{l}\text { Distance } \\
(\mathrm{cm})\end{array}$ & $\begin{array}{l}{ }^{237} \mathrm{~Np} \\
(n, j)\end{array}$ & $\begin{array}{l}{ }^{238} \mathrm{U} \\
(n, n) \\
\end{array}$ & $\begin{array}{l}{ }^{103} \mathrm{Rh} \\
\left(n, n^{\prime}\right) \\
\end{array}$ & $\begin{array}{c}{ }^{115} \mathrm{In} \\
\left(n, n^{\prime}\right) \\
\end{array}$ & $\begin{array}{l}{ }^{58} \mathrm{Ni} \\
(n, p)\end{array}$ & $\begin{array}{l}{ }^{27} \mathrm{Al} \\
(n, \alpha) \\
\end{array}$ \\
\hline $\mathrm{Al}$ & 12.0 & $\begin{array}{r}6.64 \mathrm{E}-6 \\
\pm 6.2 \% \\
\end{array}$ & - & $\begin{array}{r}5.54 \mathrm{E}-6 \\
\pm 1.0 \% \\
\end{array}$ & $\begin{array}{c}5.61 \mathrm{E}-6 \\
\pm 1.0 \% \\
\end{array}$ & $\begin{array}{r}5.83 \mathrm{E}-6 \\
\pm 1.4 \% \\
\end{array}$ & $\begin{array}{r}7.87 \mathrm{E}-6 \\
\pm 1.0 \% \\
\end{array}$ \\
\hline A2 & 23.8 & - & - & - & $\begin{array}{r}6.06 \mathrm{E}-7 \\
\pm 2.0 \% \\
\end{array}$ & $\begin{array}{r}6.18 \mathrm{E}-7 \\
\pm 2.0 \% \\
\end{array}$ & $\begin{array}{r}1.02 \mathrm{E}-6 \\
\pm 2.0 \% \\
\end{array}$ \\
\hline $\mathrm{A} 3$ & 29.7 & $\begin{array}{r}2.27 \text { E-7 } \\
\pm 6.3 \% \\
\end{array}$ & - & - & $\begin{array}{c}1.99 \mathrm{E}-7 \\
\pm 1.0 \% \\
\end{array}$ & $\begin{array}{r}2.31 \mathrm{E}-7 \\
\pm 1.4 \% \\
\end{array}$ & $\begin{array}{r}4.48 \mathrm{E}-7 \\
\pm 1.0 \% \\
\end{array}$ \\
\hline A4 & 39.5 & $\begin{array}{c}9.27 \mathrm{E}-8 \\
\pm 5.5 \% \\
\end{array}$ & $\begin{array}{c}6.11 \mathrm{E}-8 \\
\pm 6.9 \% \\
\end{array}$ & $\begin{array}{r}7.74 \mathrm{E}-8 \\
\pm 1.5 \% \\
\end{array}$ & $\begin{array}{c}5.87 \mathrm{E}-8 \\
\pm 0.7 \% \\
\end{array}$ & $\begin{array}{c}5.30 \mathrm{E}-8 \\
\pm 1.0 \% \\
\end{array}$ & $\begin{array}{r}1.02 \mathrm{E}-7 \\
\pm 2.0 \% \\
\end{array}$ \\
\hline A5 & 44.7 & $\begin{array}{c}5.18 \mathrm{E}-8 \\
\pm 5.7 \% \\
\end{array}$ & $\begin{array}{c}2.74 \mathrm{E}-8 \\
\pm 6.8 \% \\
\end{array}$ & $\begin{array}{r}4.35 \mathrm{E}-8 \\
\pm 5.0 \% \\
\end{array}$ & $\begin{array}{c}2.76 \mathrm{E}-8 \\
\pm 1.5 \% \\
\end{array}$ & $\begin{array}{c}2.09 \mathrm{E}-8 \\
\pm 1.8 \% \\
\end{array}$ & $\begin{array}{r}4.10 \mathrm{E}-8 \\
\pm 2.2 \% \\
\end{array}$ \\
\hline A6 & 50.1 & $\begin{array}{r}2.70 \mathrm{E}-8 \\
\pm 5.8 \% \\
\end{array}$ & $\begin{array}{r}1.12 \mathrm{E}-8 \\
\pm 7.1 \% \\
\end{array}$ & $\begin{array}{c}2.19 \mathrm{E}-8 \\
\pm 5.0 \% \\
\end{array}$ & $\begin{array}{c}1.17 \mathrm{E}-8 \\
\pm 3.0 \% \\
\end{array}$ & $\begin{array}{c}7.43 \text { E- } 9 \\
\pm 2.2 \% \\
\end{array}$ & $\begin{array}{r}1.54 \mathrm{E}-8 \\
\pm 2.2 \% \\
\end{array}$ \\
\hline A7 & 59.1 & $\begin{array}{r}7.25 \mathrm{E}-9 \\
\pm 9.2 \% \\
\end{array}$ & - & - & - & - & - \\
\hline \multicolumn{8}{|c|}{ Reaction cross sections, averaged over a ${ }^{235} \mathrm{U}$ fission spectrum (mb) } \\
\hline & & $\begin{array}{r}1312 \\
\pm 50 \\
\end{array}$ & $\begin{array}{r}305 \\
\pm 9 \\
\end{array}$ & $\begin{array}{r}733 \\
\pm 38 \\
\end{array}$ & $\begin{array}{r}189 \\
\pm 8 \\
\end{array}$ & $\begin{array}{l}109 \\
\pm 6 \\
\end{array}$ & $\begin{array}{r}0.705 \\
\pm 0.040 \\
\end{array}$ \\
\hline
\end{tabular}

${ }^{l}$ For the ${ }^{237} \mathrm{~Np}$ and ${ }^{238} \mathrm{U}$ equivalent fission fluxes, the combined uncertainties are given. For all others, the experimental precision only is given. (The experimental precision, as defined in Ref. 3, encompasses foil size corrections, if any; counting statistics; dead time; pileup and background corrections; corrections for interfering reactions; run-to-run monitoring; and positional uncertainties in a given experimental channel.) The combined uncertainties for ${ }^{103} \mathrm{Rh},{ }^{115} \mathrm{In},{ }^{58} \mathrm{Ni}$, and ${ }^{27} \mathrm{Al}$ equivalent fission fluxes are $\pm 6 \%$, for a precision of $1 \%$.

'Distance to core face of the aluminum window.

\subsection{HBR-2 BENCHMARK}

HBR-2 is a $2300 \mathrm{MW}$ (thermal) pressurized light water reactor designed by Westinghouse and placed in operation in March of 1971. It is owned by Carolina Power and Light Company. The core of the HBR-2 reactor consists of 157 fuel assemblies and is surrounded by the core baffle, core barrel, thermal shield, pressure vessel $(\sim 24 \mathrm{~cm}$ thick), and biological shield. A horizontal cross section of the HBR-2 is schematically shown in Fig. 2 . The HBR-2 benchmark is based on data for fuel cycle 9 . For cycle 9 , a low-leakage core loading pattern was used in which 12 previously burned fuel assemblies were put on the core periphery, on the core flat edges (i. e., around $0^{\circ}$ azimuth on Fig. 2). During cycle 9 , the relative powers of the assemblies on the core periphery changed significantly. This effect, which is often referred to as power redistribution, is caused by the fuel burnout and gradual changes of the boron concentration during the cycle, and is typically more pronounced for the low-leakage cores than for the standard (peripheral) loadings. The power redistribution affects the core neutron leakage and consequently the dosimeter reaction rates. For this reason the HBR-2 benchmark power distribution data include the cycle-averaged power distributions, and also the distributions at several time steps during the cycle. In particular, along with their cycle-average values, the assembly powers, assembly-pinpowers, and assemblywise axial power distributions are given at eight times during the cycle.

During cycle 9 , sets of radiometric monitors were irradiated in the surveillance capsule position and in several locations in the reactor cavity. A specially-built surveillance capsule containing no metallurgical specimens, but otherwise identical to a standard Westinghouse capsule, was placed in a previously used holder at the $20^{\circ}$ azimuthal location in the downcomer. The region that usually contains metallurgical specimens was filled with carbon steel and the dosimeters were installed in the holes drilled in the steel. The capsule was irradiated during cycle 9 only. The dosimeters in the cavity were irradiated in aluminum holders in order to minimize neutron flux perturbations. The holders were supported by thin stainless steel wires mounted vertically in the gap between the insulation and the biological shield. For the benchmark, the measurements with threshold radiometric monitors, irradiated in the surveillance capsule at an 
azimuthal angle of $20^{\circ}$ and in the cavity at an azimuthal angle of $0^{\circ}$, were selected. The locations of the dosimeters are shown with $x$ marks on Fig. 2 . The vertical locations of the selected dosimeters correspond to the core horizontal midplane, both for the capsule and cavity. Specific activities of the dosimeters are given in Table 2. The activities are given per $\mathrm{mg}$ of $\mathrm{Ni}, \mathrm{Fe}, \mathrm{Ti}$ and $\mathrm{Cu}$ material with naturally occurring isotopic composition, and per $\mathrm{mg}$ of ${ }^{237} \mathrm{~Np}$ and ${ }^{238} \mathrm{U}$ isotopes.

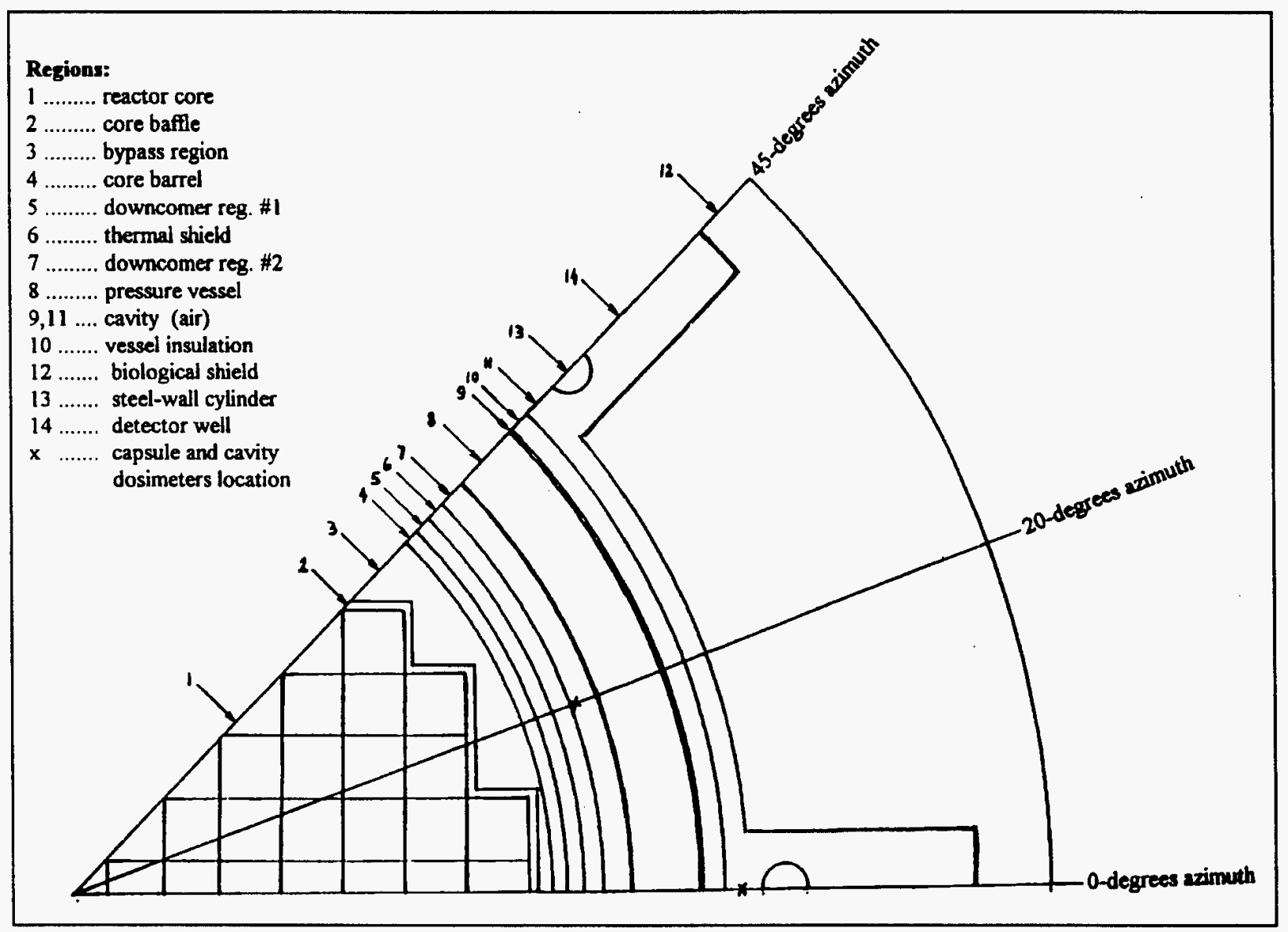

Fig. 2 Horizontal cross section of the HBR-2 reactor. One octant of the core is shown.

Table 2. Measured specific activities (in Bq/mg) of the HBR-2 dosimeters at the end of cycle 9

\begin{tabular}{|c|c|c|c|c|c|}
\hline${ }^{237} \mathrm{~Np}(n, f)^{137} \mathrm{Cs}$ & ${ }^{238} \mathrm{U}(n, f)^{137} \mathrm{Cs}$ & ${ }^{58} \mathrm{Ni}(n, p){ }^{58} \mathrm{Co}$ & ${ }^{54} \mathrm{Fe}(n, p){ }^{54} \mathrm{Mn}$ & ${ }^{46} \mathrm{Ti}(n, p)^{46} \mathrm{Sc}$ & ${ }^{63} \mathrm{Cu}(n, \alpha){ }^{60} \mathrm{Co}$ \\
\hline $3.671 \mathrm{E}+2$ & $5.345 \mathrm{E}+1$ & $1.786 \mathrm{E}+4$ & $9.342 \mathrm{E}+2$ & $3.500 \mathrm{E}+2$ & $2.646 \mathrm{E}+1$ \\
\hline \multicolumn{7}{|c|}{ Cavity } \\
\hline $2.236 \mathrm{E}+1$ & $8.513 \mathrm{E}-1$ & $1.959 \mathrm{E}+2$ & 8.711 & 3.310 & $2.645 \mathrm{E}-1$ \\
\hline
\end{tabular}

\section{BENCHMARK ANALYSIS}

The PCA and HBR-2 benchmarks were analyzed using the same methodology, computer codes, and cross sections. However, the PCA analysis was much simpler because of the easy-to-model rectangular geometry, uncomplicated neutron 
source, and absence of time-dependant variations. Therefore, the analysis of the HBR-2 benchmark will be briefly described, since it required approximations in the geometry modelling, in the neutron source preparation, and in the treatment of time dependant vatiations, which are typical for a power reactor analysis.

The neutron transport calculations were performed with the DORT computer code, which is based on the method of discrete ordinates. The synthesis method, which relies on two- and one-dimensional (2-D and 1-D) transport calculations to obtain an estimation of the neutron fluxes in three-dimensional geometries, was used. The application of the method to the HBR-2 benchmark calls for three transport calculations. One two-dimensional calculation models the horizontal cross section of the reactor in $r-\theta$ geometry and is used to compute the variations of the neutron field in the radial direction (which is the main direction of the neutron transport from the core towards the pressure vessel and beyond) and in the azimuthal direction. The second calculation is a two-dimensional calculation in cylindrical $r-z$ geometry, in which the core is modelled as a finite-height cylinder. The third calculation is made for the one-dimensional $(r)$ cylindrical model of the reactor. The $r-z$ and one dimensional $r$ calculations are combined to obtain the axial variations of the neutron field.

The geometry models used were almost identical to those used in previous HBR-2 analyses ${ }^{5.6}$. The $r-\theta$ model covered one octant of the horizontal cross section with 74 azimuthal $(\theta)$ intervals. In the radial direction, which extended from the core axis to the pressure vessel, reactor cavity and inside the concrete shield (from a radius of $0 \mathrm{~cm}$ to $345 \mathrm{~cm}$ ), the number of radial intervals was varied with azimuthal interval (variable mesh option) and ranged from 93 to 116 intervals. The surveillance capsule was included in the model. The $r-z$ model used 75 axial $(z$-axis) intervals ( 57 intervals covered the active fuel height of $366 \mathrm{~cm}$ ) and 93 radial intervals (from the axis of the core to the radius of $335 \mathrm{~cm}$ ). The $r-z$ mesh outside the core described the geometry at the azimuth of $0^{\circ}$, since the benchmark cavity dosimetry is at this azimuth. The onedimensional calculation used the same radial mesh as the $r-z$ model.

The cross sections for the transport calculations were taken from the ENDF/B-VI-based library BUGLE-96 ${ }^{7}$, and the mixtures of the homogenized zone compositions were prepared by the GIP ${ }^{8}$ code. $\mathrm{A} \mathrm{P}_{3}$ approximation to the angular dependence of the anisotropic scattering cross sections, a symmetric $S_{8}$ directional quadrature set, and 47 neutron energy groups were used for all transport calculations.

The neutron sources were prepared from the cycle-average-pin-power distributions and cycle-average assembly axial power distributions. The computer code DOTSOR was used to perform the transformation of the $y-x$ and $x-z$ distibutions into the $r-\theta, r-z$, and $r$ geometry mesh. The power-to-neutron-source conversion factor was based on the average burnup of the peripheral assemblies at the middle of cycle 9 , in order to account for the contributions of ${ }^{235} \mathrm{U}$ and ${ }^{239} \mathrm{Pu}$ to the fission neutron source. The source energy spectrum was taken as the average of ${ }^{235} \mathrm{U}$ and ${ }^{239} \mathrm{Pu}$ fission spectra.

From the three transport calculations, the neutron fluxes in the core midplane, in the surveillance capsule, and in the cavity were synthesized. Reaction rates were calculated with the CROSS-95 dosimetry library ${ }^{10}$. The calculated reaction rates corresponded to the cycle-average power distribution, which was used in the transport calculations. However, the power distribution changes during the cycle and the reaction rates at the dosimetry location are affected mostly by the changes in the closest fuel assemblies. To account for these changes during the cycle, the following approximation was used. The cycle was divided into eight time segments, based on the intervals at which the power distributions were provided. The average relative power $p_{i}$ of the three fuel elements closest to the location of the dosimetry was calculated and assumed constant during each segment. The powers $p_{i}$ were normalized so that, when integrated over the cycle, they provided the correct total energy production (i.e., the energy produced in the three fuel elements). The reaction rate during each segment was then obtained by scaling the calculated reaction rate with the ratio $\left(p_{i} / p_{D}\right)$. The $p_{i}$ was defined above and the $p_{D}$ was the cycle-average power of the same three assemblies (which was used in the transport calculation). The daily power history was then superimposed and activities were calculated. Note that different assemblies were used to calculate $p_{i}$ for the dosimeters in the capsule and in the cavity. The decision to use three assemblies to compute $p_{i}$ and $p_{D}$ was based on the knowledge that the three assemblies on the core flat edge contribute predominantly to the response of the cavity dosimeters at the azimuth of $0^{\circ}$; however, it is nevertheless rather arbitrary, especially for capsule dosimetry. This simple and inexpensive refinement in the calculation of activities improved considerably the consistency of the calculated-to-measured (C/M) ratios for the short- and longer-lived reaction products and the overall agreement of the calculated and measured activities $^{2}$

\section{RESULTS AND DISCUSSION}

Results of the PCA and HBR-2 benchmark analyses are given in Table 3 and Table 4, respectively. The PCA results are given in terms of the $\mathrm{C} / \mathrm{M}$ ratios of equivalent fission fluxes. The determination of the $\mathrm{C} / \mathrm{M}$ ratios was straightforward; the calculated reaction rates were divided by the reaction cross sections averaged over the ${ }^{233} \mathrm{U}$ fission spectrum (listed in Table 1) to obtain calculated equivalent fission fluxes, which were then divided by the measured fission fluxes (from 
Table 1). The last column on the right in Table 3 lists the arithmetic average of the $\mathrm{C} / \mathrm{M}$ ratios for all the dosimeters irradiated at the same location and the standard deviation ( $\sigma$ ) of the average.

For the HBR-2 the compared calculated and measured quantities are the specific activities of the radiometric monitors at the end of irradiation. Before the $\mathrm{C} / \mathrm{M}$ ratios were calculated, corrections were applied to the ${ }^{237} \mathrm{~Np}$ and ${ }^{238} \mathrm{U}$ measured activities (given in Table 2) to compensate for the photofission, and the ${ }^{60} \mathrm{Co}$ activity in $\mathrm{Cu}$ dosimeter was corrected to compensate for the ${ }^{59} \mathrm{Co}$ impurity. The corrections, taken from the previous work ${ }^{5}$, lowered the activities of the ${ }^{237} \mathrm{~Np}$, ${ }^{238} \mathrm{U}$, and ${ }^{63} \mathrm{Cu}$ dosimeters in the surveillance capsule by $2.5,5$, and $2.5 \%$, respectively. In the cavity, these corrections were 5.0 , 10.0 , and $2.5 \%$, respectively. Since the corrections were estimated, and are not negligible, it is worthwhile to show their effect on the $\mathrm{C} / \mathrm{M}$ ratios. For these reasons the $\mathrm{C} / \mathrm{M}$ values for the as-measured activities (without corrections) are also given in Table 4 in parentheses. The last column on the right in Table 4 lists the arithmetic average of the C/M ratios and the standard deviation of the average.

Table 3. PCA benchmark: ratios of the calculated-to-measured (C/M) equivalent fission fluxes

\begin{tabular}{|c|c|c|c|c|c|c|c|}
\hline Location $^{1}$ & ${ }^{237} \mathrm{~Np}(n, f)$ & ${ }^{238} \mathrm{U}(n, f)$ & $\begin{array}{c}{ }^{27} \mathrm{Al}(n, \alpha) \\
{ }^{24} \mathrm{Na}\end{array}$ & $\begin{array}{c}{ }^{58} \mathrm{Ni}(n, p) \\
{ }^{58} \mathrm{Co}\end{array}$ & $\begin{array}{c}{ }^{115} \mathrm{In}\left(n, n^{\prime}\right) \\
{ }^{115 \mathrm{~m}} \mathrm{In}\end{array}$ & $\begin{array}{c}{ }^{103} \mathrm{Rh}\left(n, n^{\prime}\right) \\
{ }^{103 \mathrm{~m}} \mathrm{Rh}\end{array}$ & Av. $\pm \sigma$ \\
\hline $\mathrm{Al}$ & 0.89 & - & 0.94 & 0.90 & 0.91 & 0.93 & $0.91 \pm 0.02$ \\
\hline $\mathrm{A} 2$ & - & - & 0.93 & 0.91 & 0.91 & - & $0.92 \pm 0.01$ \\
\hline $\mathrm{A} 4$ & 0.97 & - & 0.98 & 0.93 & 0.95 & - & $0.96 \pm 0.02$ \\
\hline $\mathrm{A} 5$ & 0.93 & 0.90 & 0.96 & 0.91 & 0.97 & 0.96 & $0.94 \pm 0.03$ \\
\hline $\mathrm{A} 6$ & 0.92 & 0.86 & 0.95 & 0.90 & 0.94 & 0.92 & $0.92 \pm 0.03$ \\
\hline A7 & 0.89 & 0.84 & 0.95 & 0.94 & 0.95 & 0.91 & $0.91 \pm 0.04$ \\
\hline
\end{tabular}

${ }^{4}$ Locations are shown in Fig. 1.

Table 4. HBR-2: ratios of calculated-to-measured (C/M) specific activities ${ }^{1}$

\begin{tabular}{|l|c|c|c|c|c|c|c|}
\hline & $\begin{array}{c}{ }^{237} \mathrm{~Np}(n, f) \\
{ }^{137} \mathrm{Cs}\end{array}$ & $\begin{array}{c}{ }^{238} \mathrm{U}(n, f) \\
{ }^{137} \mathrm{Cs}\end{array}$ & $\begin{array}{c}{ }^{58} \mathrm{Ni}(n, p) \\
{ }^{58} \mathrm{Co}\end{array}$ & $\begin{array}{c}{ }^{54} \mathrm{Fe}(n, p) \\
{ }^{54} \mathrm{Mn}\end{array}$ & $\begin{array}{c}{ }^{46} \mathrm{Ti}(n, p) \\
{ }^{46} \mathrm{Sc}\end{array}$ & $\begin{array}{c}{ }^{63} \mathrm{Cu}(n, \alpha) \\
{ }^{60} \mathrm{Co}\end{array}$ & $\mathrm{Av}^{2} \pm \sigma$ \\
\hline Capsule & $\begin{array}{c}0.92 \\
(0.90)\end{array}$ & $\begin{array}{c}0.89 \\
(0.85)\end{array}$ & $\begin{array}{c}0.96 \\
(0.96)\end{array}$ & $\begin{array}{c}0.93 \\
(0.93)\end{array}$ & $\begin{array}{c}0.85 \\
(0.85)\end{array}$ & $\begin{array}{c}0.93 \\
(0.90)\end{array}$ & $\begin{array}{c}0.91 \pm 0.04 \\
(0.90 \pm 0.04)\end{array}$ \\
\hline & $\begin{array}{c}0.61 \\
(0.58)\end{array}$ & $\begin{array}{c}0.82 \\
(0.74)\end{array}$ & $\begin{array}{c}0.97 \\
(0.97)\end{array}$ & $\begin{array}{c}0.96 \\
(0.96)\end{array}$ & $\begin{array}{c}0.90 \\
(0.90)\end{array}$ & $\begin{array}{c}0.96 \\
(0.93)\end{array}$ & $\begin{array}{c}0.92 \pm 0.06 \\
(0.90 \pm 0.09)\end{array}$ \\
\hline
\end{tabular}

${ }^{1}$ The corrections were applied to the ${ }^{237} \mathrm{~Np}(n, f){ }^{137} \mathrm{Cs},{ }^{238} \mathrm{U}(n, f){ }^{137} \mathrm{Cs}$, and ${ }^{63} \mathrm{Cu}(n, \alpha){ }^{60} \mathrm{Co}$ measured activities before the $\mathrm{C} / \mathrm{M}$ ratios were determined (see text). The ratios in parenthesis are for the as-measured activities (without corrections).

-Average (arithmetic) $\mathrm{C} / \mathrm{M}$ ratio and standard deviation. For the cavity location the averages are calculated without the

${ }^{237} \mathrm{~Np}(n, f){ }^{137} \mathrm{Cs}$ reaction. With ${ }^{237} \mathrm{~Np}(n, f){ }^{137} \mathrm{Cs}$ reaction the averages are $0.87 \pm 0.14(0.85 \pm 0.16)$.

The arithmetic average of the C/M ratios for all the dosimeters in the PCA (a total of 31 measurements) is $0.92 \pm 0.03$; 0.03 is the standard deviation ( $\sigma$ ) of the average. The average $\mathrm{C} / \mathrm{M}$ for the measurements in the HBR-2 (a total of 12) is $0.89 \pm 0.10$.

The larger standard deviation of the $\mathrm{C} / \mathrm{M}$ average for HBR-2 is caused mainly by the low $\mathrm{C} / \mathrm{M}$ ratio for ${ }^{237} \mathrm{~Np}$ dosimeter in the cavity. In the cavity location the average $\mathrm{C} / \mathrm{M}$ for all the dosimeters but ${ }^{237} \mathrm{~Np}$ is $0.92 \pm 0.06$, while the $\mathrm{C} / \mathrm{M}$ for ${ }^{237} \mathrm{~Np}$ 
is 0.61 ; therefore, it is more than five $\sigma$ below the average and more than $3 \sigma$ below the next lowest $\mathrm{C} / \mathrm{M}$ - that of ${ }^{238} \mathrm{U}$. (Even if the same photofission correction is used for ${ }^{237} \mathrm{~Np}$ and ${ }^{238} \mathrm{U}$, i.e. $10 \%$, the ${ }^{237} \mathrm{~Np} \mathrm{C} / \mathrm{M}$ still remains 3 o lower than $\mathrm{C} / \mathrm{M}$ of ${ }^{238} \mathrm{U}$.) This problem with the ${ }^{237} \mathrm{~Np}$ dosimeter was addressed in several analyses, but has not been conclusively explained ${ }^{11}$. Currently, the most probable explanation appears to be an incorrect measured value; however, since the measurement cannot be repeated, some doubt remains, and an alternative interpretation will be discussed later.

Excluding the ${ }^{237} \mathrm{~Np}$ cavity dosimeter for the reasons given above yields the average $\mathrm{C} / \mathrm{M}$ for HBR-2 of $0.92 \pm 0.06$, which is in excellent agreement with the PCA results. In both benchmarks good agreement of the calculations and measurements is observed. The calculations under predict the measurements by less than $10 \%$, which represents significant improvement over the results typically obtained with the pre-ENDF/B-VI cross section libraries. A comparison of the average $\mathrm{C} / \mathrm{M}$ values for the HBR-2 from the present analysis with ENDF/B-VI-based BUGLE-96 cross sections, with those from the previous analysis ${ }^{5}$ with the ENDF/B-IV-based ELXSIR library is given in Table 5. An overall improvement of $21 \%$ in the average $\mathrm{C} / \mathrm{M}$ values was obtained; with improvements of $10 \%$ in the capsule and almost $40 \%$ in the cavity. This indicates that the ENDF/B-VI cross sections resolve most of the discrepancies between the measured and calculated activities. In particular, due to reductions in the iron inelastic scattering cross section in ENDF/B-VI, the decrease of the $\mathrm{C} / \mathrm{M}$ ratios with increased thickness of iron, which was typical for pre-ENDF/B-VI libraries, is almost completely removed. The average C/M ratios obtained with BUGLE-96 show practically no decrease with increasing distance from the core and thickness of steel penetrated. The average C/M ratios in the HBR-2 capsule and cavity locations, separated by a 24-cmthick pressure vessel, are practically identical. This observation is supported by the PCA results: the average C/M ratios at the location in front of the thermal shield (Al), which is the closest to the core, and at the location at $3 / 4$ wall thickness in the pressure vessel simulator $(\mathrm{A} 6)$ are $0.91 \pm 0.02$ and $0.91 \pm 0.04$, respectively, while there is $\sim 23 \mathrm{~cm}$ of steel between the two positions. Finally, one observes also that differences in the $\mathrm{C} / \mathrm{M}$ values at all locations are small, which indicates that the calculated neutron spectrum is adequate, at least in the energy range to which the dosimeters are sensitive.

Table 5. Comparison of average C/M ratios in HBR-2'

\begin{tabular}{|c|c|c|c|}
\hline & \multicolumn{3}{|c|}{ Average C/M $\pm \sigma$} \\
\cline { 2 - 4 } & Capsule & Cavity & Capsule and Cavity \\
\hline Previous analysis (ELXSIR, based on ENDF/B-IV) & $0.83 \pm 0.03$ & $0.67 \pm 0.03$ & $0.76 \pm 0.09$ \\
\hline Present analysis (BUGLE-96, based on ENDF/B-VI) & $0.91 \pm 0.04$ & $0.92 \pm 0.06$ & $0.92 \pm 0.05$ \\
\hline Change & $10 \%$ & $37 \%$ & $21 \%$ \\
\hline
\end{tabular}

${ }^{1}$ The ${ }^{237} \mathrm{~Np}$ dosimeter in the cavity is excluded from the averages.

Returning to the discussion of the ${ }^{237} \mathrm{~Np}$ dosimeter in the HBR-2 cavity, which was eliminated in the comparisons presented above, it is interesting to observe that in the HBR-2 cavity, neutrons with energies below $\sim 1.8 \mathrm{MeV}$ generate $\sim 90 \%$ of the ${ }^{237} \mathrm{~Np}(n, f)$ response, about $50 \%$ of the ${ }^{238} \mathrm{U}(n, f)$ response, but only about $8 \%$ of the response of the ${ }^{54} \mathrm{Fe}(n, p)$, and even less of the response of the other dosimeters. Since the ${ }^{238} \mathrm{U}(n, f)$ response in the cavity is also underpredicted with respect to the other threshold dosimeters, this suggests that in the cavity the neutron fluxes below $\sim 1.8 \mathrm{MeV}$ may be underpredicted. Close examination of the $\mathrm{C} / \mathrm{M}$ ratios for individual dosimeters in the PCA pressure vessel simulator shows that the ${ }^{237} \mathrm{~Np},{ }^{103} \mathrm{Rh}$, and ${ }^{238} \mathrm{U}$ dosimeters, which are sensitive to neutrons below $\sim 1.8 \mathrm{MeV}$ all show small decreases in their $\mathrm{C} / \mathrm{M}$ ratios with increasing thickness of steel (i. e. from location $\mathrm{A} 4$ to $\mathrm{A6}$ ), while other dosimeters show much smaller or no decreases. While this decrease is not big enough to be important per se, it shows a trend that is in agreement with the observation in HBR-2, and supports the suggestion that the ENDF/B-VI cross sections may still underpredict the neutron transmission through steel in the energy range below $\sim 1.8 \mathrm{MeV}$.

The neutron fluxes leaking through the iron shield are quite sensitive to the inelastic scattering cross section of iron. Relative sensitivities are, of course, negative. An overestimated iron inelastic scattering cross section in the energy range below $\sim 1.8 \mathrm{MeV}$ may, therefore, be responsible for the underestimations such as those observed for ${ }^{237} \mathrm{~Np}$ and ${ }^{238} \mathrm{U}$ in the HBR-2 cavity. Since the largest changes in the ENDF/B-VI evaluation were done above $\sim 2 \mathrm{MeV}$, and the ${ }^{56} \mathrm{Fe}$ inelastic scattering cross section $\left[\mathrm{Fe}\left(n, n^{\prime}\right)\right]$ leading to the first excited level in ${ }^{56} \mathrm{Fe}$ has an uncertainty of about $5-10 \%$ in the range from 0.847 to $\sim 5 \mathrm{MeV}^{12}$, further improvements in the $\mathrm{Fe}$ inelastic cross section may be necessary. 


\section{CONCLUSIONS}

The PCA and HBR-2 benchmarks provide input which may be used for a part of the qualification of the pressure vessel fluence calculational methodology, as required by the U. S. Nuclear Regulatory Commission Draft Regulatory Guide DG1053 entitled "Calculational and Dosimetry Methods for Determining Pressure Vessel Neutron Fluence".

The benchmarks were analyzed using the DORT computer code and BUGLE-96 cross-section library. The study confirmed the completeness of the PCA and HBR-2 benchmarks and their usefulness for testing certain aspects of the calculational methodology. In particular, the comparison of the present results with the previous calculations with ENDF/B-IV data clearly showed that the benchmark results strongly depend on one crucial component of the calculational methodology: the cross sections used in transport calculation. The HBR-2 results were also found to be quite sensitive to the treatment of time-dependant variations in the core power distribution, although this was not fully presented in the paper.

The PCA and HBR-2 benchmark analysis showed that the ENDF/B-VI cross sections (used for the BUGLE-96 multigroup library) resolve most of the discrepancies between the measured and calculated dosimeter responses. The calculations agreed with the measurements within $\sim 10 \%$, and the calculations underpredicted the measurements in all cases. The decrease of the C/M ratios with increased thicknesses of iron, which was typical for pre-ENDF/B-VI libraries, is almost completely removed. Some indications were found that the ENDF/B-VI cross sections may still underestimate neutron leakage through thick layers of steel at energies below $\sim 1.8 \mathrm{MeV}$; however, further investigation is necessary.

\section{ACKNOWLEDGEMENTS}

The author gratefully acknowledges the financial support and encouragement provided by the U. S. Nuclear Regulatory Commission, particularly Carolyn Fairbanks and Mike Maytield. The author also wishes to thank W. K. Cantrell, C. S. Hinnant, and R. M. Kirsh of the Carolina Power and Light Company for providing core depletion calculations for HBR-2, cycle 9. Special thanks go to F. B. K. Kam and J. V. Pace III of the Oak Ridge National Laboratory for their help and invaluable advice during the work.

\section{REFERENCES}

1. I. Remec and F. B. K. Kam, Pool Critical Assembly Pressure Vessel Facility Benchmark, NUREG/CR-6454 (ORNL/TM-13205), July 1997.

2. I. Remec and F. B. K. Kam, H. B. Robinson-2 Pressure Vessel Benchmark, NUREG/CR-6453 (ORNL/TM-13204), October 1997.

3. W. N. McElroy, ed., LWR Pressure Vessel Surveillance Dosimetry Improvement Program: PCA Experiments and Blind Test, NUREG/CR-1861 (HEDL-TME 80-87, R5), July 1981.

4. W. A. Rhoades et al., "TORT-DORT Two- and Three-Dimensional Discrete Ordinates Transport, Version 2.8.14," CCC-543, Radiation Shielding Information Center, Oak Ridge National Laboratory, 1994.

5. R. E. Maerker, "LEPRICON Analysis of the Pressure Vessel Surveillance Dosimetry Inserted into H. B. Robinson-2 During Cycle 9," Nuc. Sci. Eng., 96:263 (1987).

6. M. L. Williams, M. Asgari, F. B. K. Kam, Impact of ENDF/B-V7 Cross-Section Data on H. B. Robinson Cycle 9 Dosimetry Calculations, NUREG/CR-6071 (ORNL/TM-12406), October 1993.

7. J. E. White et al.,"BUGLE-96: Coupled 47 Neutron, 20 Gamma-Ray Group Cross Section Library Derived from ENDF/B-VI for LWR Shielding and Pressure Vessel Dosimetry Applications," RSIC Data Library Collection, DLC-185, March 1996.

8. W. A. Rhoades,"The GIP Program for Preparation of Group-Organized Cross Section Libraries," informal notes, November 1975, RSIC Peripheral Shielding Routine Collection PSR-75.

9. M. L. Williams, "DOTSOR: A Module in the LEPRICON Computer Code System for Representing the Neutron Source Distribution in LWR Cores," EPRI Research Project 1399-1 Interim Report (Dec. 1985), RSIC Peripheral Shielding Routine Collection PSR-277.

10. I. Remec and F. B. K. Kam, An Update of the Dosimetry Cross-Section Data Base for the Adjustment Code LSLM2, ORNL/NRC/LTR-95/20, June 1995.

II. I. Remec, Analysis of the Discrepancy in the ${ }^{237} \mathrm{~Np}$ Dosimeter for the H. B. Robinson Unit 2 Cavity Benchmark Experiment, Cycle 9: Initial Phase, ORNL/NRC/LTR-97/6, March 1997.

12. P. F. Rose, ed., ENDF/B-VI Summary Documentation, BNL-NCS-1754I (ENDF-201), 4th ed., National Nuclear Data Center, Brookhaven National Laboratory, October 1991. 
84

Two Benchmarks for Qualification of Pressure Vessel Fluence Calculational Methodology author

Remec, Igor

Oak Ridge National Laboratory, P.O. Box 2008, Oak Ridge, TN 37831-6363

423.574.7076

423.574 .9619

remeci@ornl.gov

end author

Neutron Transport Calculations

Benchmark

Reactor Pressure Vessel

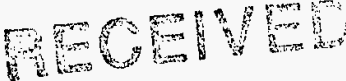

MAR 301998

OSTI 


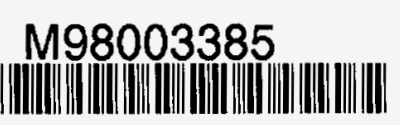

Report Number (14) Dele /CP--96966

Publ. Date (11)

Sponsor Code (18) DOE, NRC, XF

UC Category (19) UC-900; UC-COC, DOE/ER

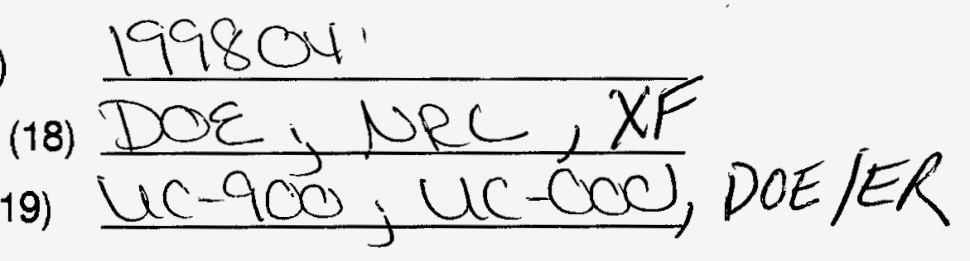

